\title{
Dampak Pencemaran Mikroplastik di Ekosistem Laut terhadap Zooplankton : Review
}

\author{
Impact of Microplastics Pollution in Marine Ecosystem to \\ Zooplankton : A Review
}

\author{
Mardiyana $^{1^{*}}$, Ari Kristiningsih ${ }^{2}$ \\ ${ }^{1,2}$ Program Studi Teknik Mesin Perikanan, Politeknik Negeri Cilacap, Jalan Dr. Soetomo No. \\ 1 Sidakaya, Cilacap, 53212 \\ Email: ${ }^{1}$ mardiyana@pnc.ac.id, ${ }^{2}$ ari.kristiningsih@pnc.ac.id \\ Direview : 10 Februari 2020 \\ Diterima : 26 Februari 2020
}

\begin{abstract}
Abstrak
Pencemaran yang bersumber dari mikroplastik merupakan salah satu permasalahan global. Sampah plastik masuk ke laut baik secara sengaja maupun tidak disengaja dan akan terdegradasi menjadi mikroplastik. Ukuran mikroplastik yang kecil dan cenderung mengapung di kolom air sehingga mudah termakan oleh organisme laut, salah satunya adalah zooplankton. Mikroplastik yang termakan oleh zooplankton, memberikan dampak negatif baik untuk zooplankton itu sendiri maupun untuk ekosistem. Dampak mikroplastik pada zooplankton mengganggu fekunditas, kapasitas makan, mengganggu sistem pencernaan, kandungan fesesnya serta memberikan efek akut dan kronis. Dampak bagi ekosistem laut memungkinkan terjadinya transfer mikroplastik melalui rantai makanan (trophic transfer) karena zooplankton memiliki peran penting dalam ekologi. Review ini membahas mengenai distribusi dan degradasi mikroplastik, proses masuknya mikroplastik ke dalam zooplankton, dampaknya pada zooplankton serta dampak terhadap ekosistem Laut. Kajian ini menjadi penting agar dapat memberi informasi kepada para peneliti sebagai dasar dalam pengelolaan sumberdaya perairan.
\end{abstract}

Kata kunci: ekosistem, mikroplastik, organisme, pencemaran, zooplankton.

\begin{abstract}
Microplastics pollution is one of the global problems. Plastic garbage entry in the ocean either intentionally or unintentionally and willbe degraded into microplastics. Microplastics size is small and float in water coloumn so make it easy to ingested by marine organisms,one of which is zooplankton. Zooplankton ingested microplastics and may impact upon zooplankton also the ecosystem. Microplastics can influence the fucundity, the feeding capacity, impact on digestion system, faecal pellet properties, and also provide accute and chronic effects on zooplankton. Impact on marine ecosystems allow microplastics transfers through food chain (trophic transfer) because of zooplankton have an important role in ecosystems. This review summarized the current knowledge about distribution and degradation of microplastics, ingestion of microplastics by zooplankton, the impact on zooplankton and also to the marine ecosystems. This study is important to provide basic information to researchers in marine resources management.
\end{abstract}

Keywords: ecosystem, microplastics, organisms, pollution, zooplankton. 


\section{Pendahuluan}

Pencemaran yang bersumber dari mikroplastik merupakan salah satu permasalahan global yang saat ini sedang menjadi sorotan bagi para pemerhati lingkungan. Permasalahan mikroplastik ini memberikan gambaran dalam penggunaan plastik dikehidupan sehari-hari yang menyebabkan kerusakan ekologi karena pembuangan sampah plastik yang sembarangan (tidak memperhatikan dampak dimasa mendatang) (Galloway, Cole, \& Lewis, 2017).

Sampah plastik menjadi salah satu ancaman serius bagi ekosistem laut. Lebih dari 690 spesies laut telah terdampak oleh sampah plastik ini baik yang berukuran puing-puing (debris) maupun yang kecil (mikroplastik) yang teramati di saluran pencernaan organisme dari berbagai tingkatan trofik rantai makanan (Carbery, O'Connor, \& Palanisami, 2018).

Mikroplastik banyak ditemukan di wilayah laut yang dekat dengan kegiatan manusia (pesisir dan estuari), termasuk pengeboran minyak dan perkapalan (Castillo, Al-Maslamani, \& Obbard, 2016), industri dan pelabuhan (Frias, Otero, \& Sobral, 2014). Kandungan mikroplastik tertinggi biasanya ditemukan pada musim penghujan, disaat lingkungan pesisir banyak mendapat masukan air dari sungai yang banyak mengandung fragmen-fragmen dari plastik melalui muara (runoff).

Ukuran mikroplastik yang kecil dan cenderung mengapung di kolom air sehingga mudah masuk dan terakumulasi pada organisme laut (Cordova, Purwiyanto, \& Suteja, 2019). Salah satu organisme yang dapat memakan mikroplastik yakni zooplankton. Zooplankton pada jenis meroplankton merupakan tahapan juvenil dari spesies yang memiliki nilai ekonomis tinggi seperti larva Bivalvia, Brachyura (megalopa), larva Caridae, larva Paguridae, dan Porcellanidae. Jenis-jenis meroplankton tersebut teridentifikasi memakan mikroplastik baik secara utuh maupun sebagian (Cole et al., 2013). Secara umum zooplankton

DOI : 10.35970/jppl.v2i1.147

Corresponding Author : mardiyana@pnc.ac.id dapat memakan mikroplastik yang memiliki diameter 1,4-30,6 $\mu \mathrm{m}$ dengan kapasitas yang berbeda-beda tergantung spesies dan ukuran mikroplastik (Cole et al., 2013).

Mikroplastik yang termakan memberikan dampak pada zooplankton itu sendiri, tetapi juga terhadap ekosistem. Hal ini dikarenakan zooplankton memiliki peran penting dalam ekologi.

Kajian-kajian seperti ini menjadi penting agar dapat memberi informasi kepada para peneliti sebagai dasar dalam tindak pengelolaan sumberdaya perairan. Review ini membahas mengenai distribusi dan degradasi mikroplastik, proses masuknya mikroplastik ke dalam zooplankton dan dampaknya pada zooplankton serta dampak terhadap ekosistem Laut.

\section{Metodologi}

Pencarian literatur yang komprehensif mengenai mikroplastik yang ada di zooplankton telah dilakukan dengan bantuan mesin pencari komersil yakni

setac.onlinelibrary.wiley.com/,pubs.acs. org/ojs.unud.ac.id/, link.springer.com/, sciencedirect.com.

\section{Distribusi dan Degradasi Mikroplastik di Perairan}

Setiap tahun, jutaan metrik ton plastik diproduksi untuk kemasan makanan, produk perawatan kecantikan, alat tangkap, dan aktivitas manusia lainnya yang berujung masuk ke laut baik secara sengaja maupun tidak disengaja. Partikel turunan plastik ini yang dikenal dengan mikroplastik telah terdeteksi di semua samudera di dunia dan juga di banyak ekosistem air tawar, terakumulasi dalam sedimen, di garis pantai, tersuspensi di kolom air dan dicerna oleh plankton, ikan, burung, dan mamalia laut (Lin, 2016).

$$
\text { Densitas mikroplastik }
$$
menentukan persebarannya di kolom air. Secara umum, jenis PE (polyetilen) dan PP (polypropilen) akan mengambang 
karena densitasnya lebih kecil dibandingkan dengan air sedangkan jenis PVC (polyvinylidene chloride), PS (polystiren), PET dan PA (polyamide) yang memiliki densitas lebih besar dari air sehingga akan cenderung tenggelam di kolom air (Guo \& Wang, 2019). Ukurannya yang sangat kecil sehingga mikroplastik ini tidak mudah terlihat dengan mata telanjang bahkan jenis mesoplastik yang dicampur dengan pasir masih sulit untuk dibedakan (Andrady, 2011).

Distribusi mikroplastik di perairan semakin mendapat perhatian karena mikroplastik dapat termakan oleh organisme laut. Distribusi mikroplastik di ekosistem laut dipengaruhi baik oleh faktor abiotik (faktor hidrodinamika laut) maupun faktor biotik (Castillo et al., 2016); (Lin, 2016). Mikroplastik tersebut tersebar pada kolom air, di sedimen dekat dengan pantai, dan di sedimen laut dalam (Joesidawati, 2018) atau akan masuk ke tubuh manusia melalui konsumsi biota yang memakan mikroplastik secara tidak sengaja (Gambar 1). Proses degradasinya dapat disebabkan oleh faktor mekanik, mikroba, dan fotodegradasi (Lin, 2016).

Mikroplastik yang berada di perairan dapat mengalami degradasi dan perubahan komposisi karena cahaya matahari, radiasi panas, oksidasi, dan pertumbuhan biofilm sinar matahari. Proses degradasi ini menyebabkan perubahan bentuk ukuran menjadi lebih kecil (size reduction), terjadi perubahan densitas dan warna, perubahan morfologi permukaan, dan perubahan kristalinitas (Gambar 2) (Guo \& Wang, 2019).

Degradasi umumnya diklasifikasikan berdasarkan agensi penyebab degradasi tersebut (Andrady, 2011) :

a. Biodegradasi (organisme hidup biasanya mikroba)

b. Fotodegradasi (cahaya matahari UV-B)

c. Termooksidasi (kerusakan oksidatif lambat pada suhu normal)

d. Degradasi termal (suhu tinggi)

e. Hidrolisis (reaksi dengan air; biasanya tidak signifikan di air laut).

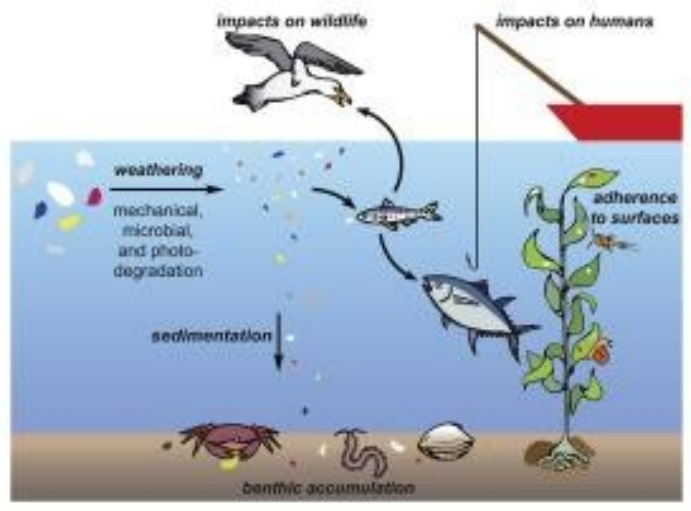

Gambar 1. Mikroplastik di Ekosistem Laut (Lin, 2016).

Proses degradasi makroplastik
menjadi mikroplastik biasanya membutuhkan waktu yang lama hingga bertahun-tahun. Hasil penelitian (Weinstein, Crocker, \& Gray, 2016) menunjukkan bahwa proses degradasi makroplastik menjadi mikroplastik relatif lebih cepat terjadi di rawa asin, hanya memerlukan waktu 8 minggu untuk jenis-jenis polyetilen densitas tinggi, polypropylen, dan polystyren.

\section{Proses Masuknya Mikroplastik pada Zooplankton}

Ukuran mikroplastik yang sangat kecil sehingga dapat dengan mudah termakan oleh ikan (Yudhantari, Hendrawan, \& Ria Puspitha, 2019) kerang (Mytilus edulis) (Von Moos, Burkhardt-Holm, \& Köhler, 2012), cacing laut, burung laut bahkan biota planktonik seperti zooplankton juga dapat memakan mikroplastik ini secara tidak sengaja (Cole et al., 2013, 2016). 
Mikroplastik masuk ke zooplankton secara tidak sengaja disebabkan sifat dari zooplankton dalam mencari makan yaitu dengan menyaring (filter feeding) lalu akan keluar melalui fesesnya dan proses masuknya berlangsung dalam hitungan jam.
Dampak mikroplastik yang masuk ke dalam tubuh zooplankton menyebabkan kinerja fisiologi berkurang, fesesnya mengandung mikroplastik dan memungkinkan terjadinya transfer kontaminan ke predator (Cole et al., 2013, 2016).

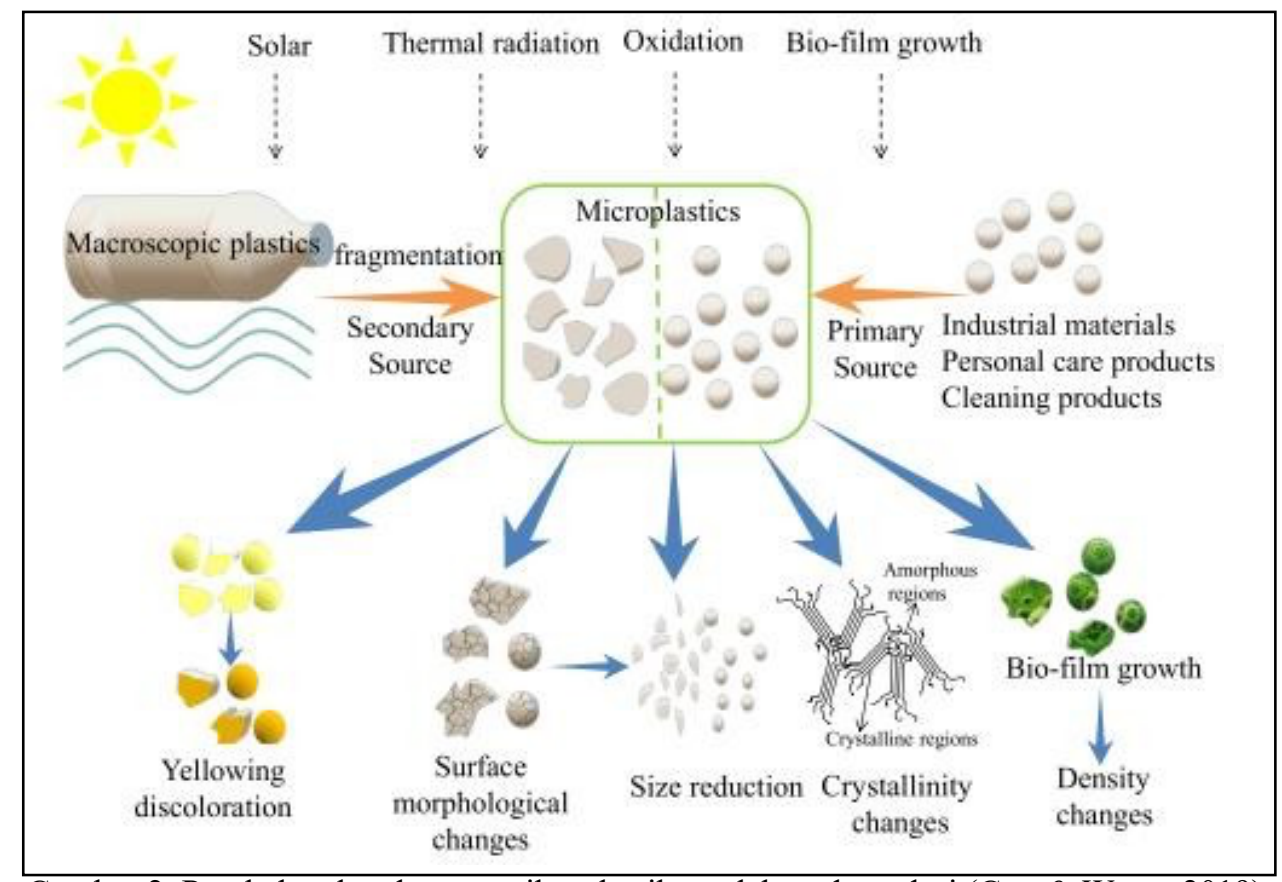

Gambar 2. Perubahan kandungan mikroplastik setelah terdegradasi (Guo \& Wang, 2019).

Proses masuknya mikroplastik pada Copepoda (Gambar 3) dan Euphasid bergantung pada kecepatan gerakan kaki renangnya dan bagian tubuh luar (external appendages) yang menghasilkan gerakan air yang masuk ke dalam mulut dan akan menyaring makanan serta semua benda yang masuk (selain makanan dalam hal ini mikroplastik). Zooplankton jenis Doliolid, proses masuknya mikroplastik melalui anterior lalu tersedot (siphon) ke dalam rongga tubuh lalu butiran polystyrene terperangkap menuju usus. Proses masuknya mikroplastik pada Oxyrrhis marina salah satu jenis dinoflagellata berbeda dengan Copepoda maupun Doliolid. Dinoflagellata ini menggunakan flagelanya untuk mencari kemudian menelan butiran polystyrene (Cole et al., 2013).

\section{Dampak Mikroplastik terhadap Zooplankton}

DOI : $10.35970 /$ jppl.v2i1.147

Corresponding Author : mardiyana@pnc.ac.id
Mikroplastik yang tertelan oleh zooplankton memberikan banyak dampak buruk bagi zooplankton itu sendiri. Keberadaannya dalam tubuh zooplankton dapat mengganggu sistem fisiologi tubuhnya. Beberapa peneliti melaporkan bahwa mikroplastik ini terbukti mengganggu fekunditas (reproduksi) (Cole, Lindeque, Fileman, Halsband, \& Galloway, 2015), kapasitas makan (Cole et al., 2015), mengganggu pencernaan (Eltemsah \& Bøhn, 2019), dampak lainnya yakni mempengaruhi feses yang dikeluarkan oleh zooplankton (Cole et al., 2016) (Gambar 3) hingga memberikan efek akut dan kronis (Eltemsah \& Bøhn, 2019).

Copepoda yang terpapar mikroplastik dalam jangka waktu yang lama akan memproduksi telur dengan ukuran yang lebih kecil dan tingkat penetasannya berkurang. Namun, tidak ada perubahan signifikan pada rasio produksi telur atau rasio konsumsi 
oksigen selama observasi (Cole et al., 2015).

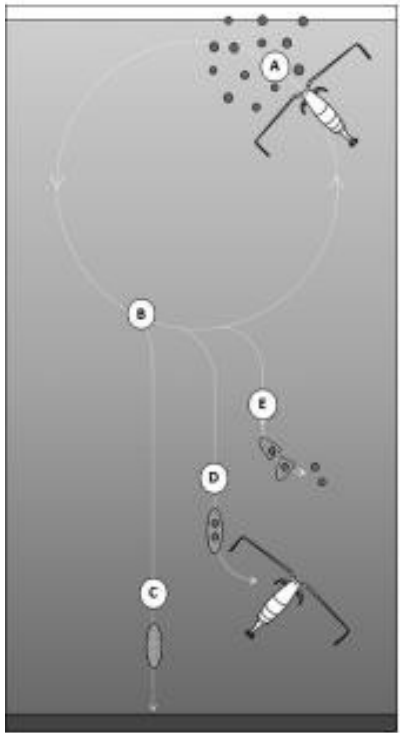

Gambar 3. Skema transport mikroplastik melalui zooplankton di kolom air. [A]

Zooplankton memakan mikroplastik di zona eufotik; [B] Zooplankton mencerna

mikroplastik dan keluar melalui feses (faecal pellets disingkat FP) di kolom air bagian atas; [C] Secara normal FP terdiri dari bahan organik, cepat tenggelam; dan [D] FP terdiri dari mikroplastik sehingga lebih lambat tenggelam memungkinkan untuk termakan lagi atau [E] terfragmentasi (Cole et al., 2016).

Mikroplastik yang termakan oleh zooplankton menyebabkan adanya penurunan kecepatan makannya. Hal ini

disebabkan mikroplastik yang masuk akan memenuhi pencernaan sehingga biota akan merasa kenyang palsu. Penelitian (Cole et al., 2015) menunjukkan Copepoda yang terpapar mikroplastik, mengalami penurunan jumlah alga yang dimakan sebesar $11 \%$.

Kajian (Eltemsah \& Bøhn, 2019) menunjukkan mikroplastik memiliki peran dalam mengganggu pencernaan Daphnia magna seperti penyaringan makannya tersumbat, dan pencernaan (ususnya berisi mikroplastik). Mikroplastik juga dapat terakumulasi dan masuk ke rantai makanan melalui biota yang memakannya secara tidak sengaja. Hasil pengamatan (Cole et al., 2013) pada Copepoda (Centropages typicus) yang memakan mikroplastik 7,3 $\mu \mathrm{m}$ (Gambar
4) menunjukkan dampak yang signifikan pada tingkat mencerna alga.

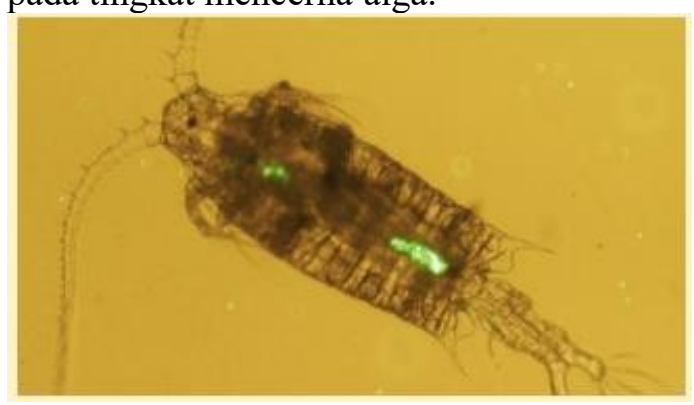

Gambar 4. Terdapat 7,3 $\mu \mathrm{m}$ butiran polystyrene (ditandai dengan fluorescent microspheres) di dalam sentrofagus Copepoda (zooplankton) (tampak dorsal) (Cole et al., 2013).

Mikroplastik juga memberikan efek akut dan kronis terhadap zooplankton. Efek akut dilihat dari efek konsentrasi mikroplastik yang menyebabkan kematian sebanyak $50 \%$ atau yang dikenal dengan uji toksisitas $\mathrm{EC}_{50}$. Hasil uji menunjukkan bahwa mikroplastik tidak memberikan efek akut pada Daphnia magna selama 48 jam tetapi memberikan efek akut (kematian) selama 120 jam. Mikroplastik ini juga dianalisis pada setiap siklus hidupnya, dan menunjukkan juvenil sebagian besar (50 \%) lebih sensitif daripada organisme dewasa dengan konsentrasi sebanyak 30 $\mu \mathrm{g} / \mathrm{ml}$ (Eltemsah \& Bøhn, 2019).

\section{Dampak Mikroplastik di Zooplankton terhadap Ekosistem Laut}

Mikroplastik yang termakan oleh zooplankton tidak hanya memberikan dampak pada zooplankton itu sendiri, tetapi juga terhadap ekosistem laut. Hal ini dikarenakan zooplankton memiliki peran penting dalam ekologi sebagai makanan utama bagi biota-biota karnivora kecil seperti larva udang, larva bivalvia, dan ikanikan kecil. Zooplankton (planktonic organisms) yang memakan mikroplastik dapat termakan oleh udang yang merupakan organisme dari satu tingkat trofik yang lebih tinggi sehingga dampaknya akan terjadi transfer mikroplastik (trophic transfer) (Gambar 5) dalam rantai makanan dan 
memungkinkan terjadinya akumulasi dalam jaring makanan (Carbery et.al, 2018);(Panti et al., 2015); (Setälä, Fleming-Lehtinen, \& Lehtiniemi, 2014). Kepadatan mikroplastik di kolom air akan menentukan bioavailabilitas mikroplastik pada zooplankton (Botterell et al., 2019) yang kemudian akan memungkinkan terjadinya transfer mikroplastik untuk organisme tingkat tinggi (predator) (Lima, Costa, \& Barletta, 2014).

Zooplankton (spesies di level tropik bawah dalam jaring makanan ekosistem laut) yang memakan mikroplastik tersebut memberikan resiko juvenil ikan Salmon mengkonsumsi 2-7 partikel mikroplastik per hari dan $\leq 91$ partikel mikroplastik pada Salmon dewasa yang ada di pesisir Columbia. Zooplankton yang diamati ada 2 yaitu Neocalanus cristatus (copepoda) dan Euphausia pacifia (euphasiid) (Desforges, Galbraith, \& Ross, 2015).

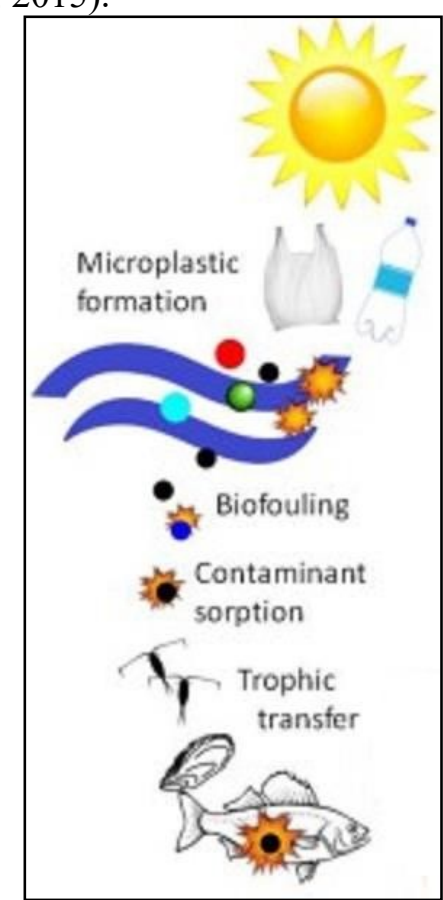

Gambar 5. Proses Trophic Transfer

Mikroplastik melalui Zooplankton (Carbery et al., 2018).

\section{Kesimpulan}

Mikroplastik yang saat sudah banyak tersebar di perairan laut akibat aktivitas manusia banyak menyebabkan dampak negatif untuk biota-biota yang ada di laut. Salah satu biota yang terdampak mikroplastik adalah zooplankton. Mikroplastik yang masuk ke zooplankton bisa menyebabkan penurunan fungsi fisiologis zooplankton, bahkan menyebabkan efek akut maupun kronis. Zooplankton memiliki peran penting dalam ekologi, sehingga sangat besar kemungkinannya terjadi transfer mikroplastik melalui rantai makanan (trophic transfer) bahkan bisa masuk ke tubuh manusia melalui rantai makanan atau jaring makanan. Penelitian mengenai mikroplastik di zooplankton masih sangat sedikit dilakukan di perairan Indonesia, sehingga perlu dilakukan tindak lanjut agak bisa memberikan informasi bagi pengelolaan sumber daya perairan.

\section{Daftar Pustaka}

Andrady, A. L. (2011). Microplastics in the marine environment. Marine Pollution Bulletin, 62(8), 15961605. https://doi.org/10.1016/j.marpolbul .2011 .05 .030

Botterell, Z. L. R., Beaumont, N., Dorrington, T., Steinke, M., Thompson, R. C., \& Lindeque, P. K. (2019). Bioavailability and effects of microplastics on marine zooplankton: A review. Environmental Pollution, 245, 98110. https://doi.org/10.1016/j.envpol.20 18.10 .065

Carbery, M., O'Connor, W., \& Palanisami, T. (2018). Trophic transfer of microplastics and mixed contaminants in the marine food web and implications for human health. Environment International, 115(March), 400-409. https://doi.org/10.1016/j.envint.201 8.03.007

Castillo, A. B., Al-Maslamani, I., \& Obbard, J. P. (2016). Prevalence of microplastics in the marine waters of Qatar. Marine Pollution Bulletin, 111(1-2), 260-267. https://doi.org/10.1016/j.marpolbul .2016 .06 .108

Cole, M., Lindeque, P., Fileman, E., Halsband, C., \& Galloway, T. S. 
(2015). The impact of polystyrene microplastics on feeding, function and fecundity in the marine copepod Calanus helgolandicus. Environmental Science and Technology, 49(2), 1130-1137. https://doi.org/10.1021/es504525u

Cole, M., Lindeque, P., Fileman, E., Halsband, C., Goodhead, R., Moger, J., \& Galloway, T. S. (2013). Microplastic ingestion by zooplankton. Environmental Science and Technology, 47(12), 6646-6655.

https://doi.org/10.1021/es400663f

Cole, M., Lindeque, P. K., Fileman, E., Clark, J., Lewis, C., Halsband, C., \& Galloway, T. S. (2016). Microplastics Alter the Properties and Sinking Rates of Zooplankton Faecal Pellets. Environmental Science and Technology, 50(6), 3239-3246.

https://doi.org/10.1021/acs.est.5b0 5905

Cordova, M. R., Purwiyanto, A. I. S., \& Suteja, Y. (2019). Abundance and characteristics of microplastics in the northern coastal waters of Surabaya, Indonesia. Marine Pollution Bulletin, 142(October 2018), 183-188. https://doi.org/10.1016/j.marpolbul .2019.03.040

Desforges, J. P. W., Galbraith, M., \& Ross, P. S. (2015). Ingestion of Microplastics by Zooplankton in the Northeast Pacific Ocean. Archives of Environmental Contamination and Toxicology, 69(3), 320-330. https://doi.org/10.1007/s00244015-0172-5

Eltemsah, Y. S., \& Bøhn, T. (2019). Acute and chronic effects of polystyrene microplastics on juvenile and adult Daphnia magna. Environmental Pollution, 254, 112919.

https://doi.org/10.1016/j.envpol.20 19.07.087

Frias, J. P. G. L., Otero, V., \& Sobral, P. (2014). Evidence of microplastics in samples of zooplankton from Portuguese coastal waters. Marine

DOI : $10.35970 /$ jppl.v2i1.147

Corresponding Author : mardiyana@pnc.ac.id
Environmental Research, 95, 8995. https://doi.org/10.1016/j.marenvres .2014.01.001

Galloway, T. S., Cole, M., \& Lewis, C. (2017). Interactions of microplastic debris throughout the marine ecosystem. Nature Ecology and Evolution, 1(5), 1-8. https://doi.org/10.1038/s41559017-0116

Guo, X., \& Wang, J. (2019). The chemical behaviors of microplastics in marine environment: A review. Marine Pollution Bulletin, 142(February), $1-14$.

https://doi.org/10.1016/j.marpolbul .2019.03.019

Joesidawati, M. I. (2018). Pencemaran mikroplastik di sepanjang pantai kabupaten Tuban. Seminar Nasional Hasil Penelitian Dan Pengabdian Masyarakat 3, (September), 7-15.

Lima, A. R. A., Costa, M. F., \& Barletta, M. (2014). Distribution patterns of microplastics within the plankton of a tropical estuary. Environmental Research, 132, 146-155.

https://doi.org/10.1016/j.envres.20 14.03.031

Lin, V. S. (2016). Research highlights: Impacts of microplastics on plankton. Environmental Science: Processes and Impacts, 18(2), 160-163. https://doi.org/10.1039/c6em90004 f

Panti, C., Giannetti, M., Baini, M., Rubegni, F., Minutoli, R., \& Fossi, M. C. (2015). Occurrence, relative abundance and spatial distribution of microplastics and zooplankton NW of Sardinia in the Pelagos Sanctuary Protected Area, Mediterranean Sea. Environmental Chemistry, 12(5), 618-626. https://doi.org/10.1071/EN14234

Setälä, O., Fleming-Lehtinen, V., \& Lehtiniemi, M. (2014). Ingestion and transfer of microplastics in the planktonic food web. Environmental Pollution, 185, 77 - 
83.

https://doi.org/10.1016/j.envpol.20 13.10.013

Von Moos, N., Burkhardt-Holm, P., \& Köhler, A. (2012). Uptake and effects of microplastics on cells and tissue of the blue mussel Mytilus edulis L. after an experimental exposure. Environmental Science and Technology, 46(20), 11327-11335. https://doi.org/10.1021/es302332w

Weinstein, J. E., Crocker, B. K., \& Gray, A. D. (2016). From macroplastic to microplastic: Degradation of high-density polyethylene, polypropylene, and polystyrene in a salt marsh habitat. Environmental Toxicology and Chemistry, 35(7), 1632-1640. https://doi.org/10.1002/etc.3432

Yudhantari, C. I., Hendrawan, I. G., \& Ria Puspitha, N. L. P. (2019). Kandungan Mikroplastik pada Saluran Pencernaan Ikan Lemuru Protolan (Sardinella Lemuru) Hasil Tangkapan di Selat Bali. Journal of Marine Research and Technology, 2(2), 48. https://doi.org/10.24843/jmrt.2019. v02.i02.p10 